\title{
Technology Attractiveness and Its Impact on MOOC Continuance Intention
}

\author{
https://doi.org/10.3991/ijet.v17i04.28853 \\ Syahrul A. Suriazdin ${ }^{1}(\varpi)$, Achmad N. Hidayanto ${ }^{1}$, Mutia Maulida $^{2}$, \\ Alverio Y. Kurtinus ${ }^{1}$, Hanifa Arrumaisha ${ }^{1}$, Nurul Aisyah ${ }^{1}$, Rico P. Pradana ${ }^{1}$ \\ ${ }^{1}$ University of Indonesia, Jakarta, Indonesia \\ ${ }^{2}$ Lambung Mangkurat University, Banjarmasin, Indonesia \\ syahrul.alameui.ac.id
}

\begin{abstract}
Massive Online Open Course (MOOC) is a web-based interactive online learning medium that allows users to take its courses and get completion certificates. The number of MOOC users does not run straight with the total rate of course completion. This is due to various user reasons, such as just to search for specific materials or sources without completing the course. Until now, there are still few studies that discuss the continuance intention to use MOOC. Thus, this study aims to evaluate a user's desire to keep learning using MOOC in zenius.net with a combination of technology attractiveness theory and expectation confirmation model. A quantitative study was conducted by distributing questionnaires to 164 respondents. The result shows that a user's desire to keep learning through MOOC was directly influenced by the level of user satisfaction. User satisfaction is directly affected by perceived benefits as well as the user's evaluation of his or her expectations on MOOC. The benefits felt by users are directly affected by Task Attractiveness and the user's evaluation of his or her expectations on MOOC. While the user's evaluation of his expectations on MOOC is directly influenced by the three factors of Technology Attractiveness, namely Task Attractiveness, Social Attractive-ness, and Physical Attractiveness.
\end{abstract}

Keywords-MOOC, expectation confirmation model, technology attractiveness, continuance intention

\section{Introduction}

Massive Online Open Course (MOOC) is a web-based interactive online learning medium that supports learning about specific concepts and can be accessed anywhere and anytime [1], [2]. The concept and application of MOOC have gained attention from academics and the e-learning industry [3], such as Zenius Education (zenius.net) from the Indonesian e-learning industry. According to the Class Central MOOC Report [4], MOOC users have reached 101 million people worldwide and more than 900 universities have launched 11,400 MOOC platforms. However, the total rate of course completion on MOOCs only reaches 5-15\% [5]. That describes only about 15 million 
students completing the course they started on their own so it was found that the low consistency of learning from MOOC users. Even though, by completing a course, the student will get a certificate related to the course taken [6]. Many students visit MOOCs only to find specific materials or resources, not to complete a course itself. In addition, some of them do not want any certificates [2].

The selection of MOOCs as a learning medium is certainly influenced by some factors. Various theories have described human behavior towards MOOC learning, such as the technology attractiveness theory and expectation confirmation model. Technology Attractiveness is a fundamental theory that researchers use to examine users' desire to keep learning through MOOCs [7]. According to [8], the attractiveness of technology will increase the desire of its users to continue to use it. To evaluate technology attractiveness, three important aspects related to attractiveness can be used, namely task attractiveness, social attractiveness, and physical attractiveness. This theory will be associated with the expectancy confirmation model.

Expectation Confirmation Model (ECM) is a theoretical framework that addresses customer satisfaction and IS continuance usage intention [9]. In this study, ECM was used to evaluate technology attractiveness factors in the user's desire to keep learning through MOOC (zenius.net), which consists of four main components, namely confirmation, perceived usefulness, satisfaction, and continuance usage intention.

According to [3], many researchers discuss MOOC, but only a few do quantitative research related to continuance usage intentions at MOOC. Shen et al. [8] researched interpersonal attraction theory and relationship management. The study proposes a research model to address the influence of technology attractiveness, which consists of task attractiveness, social attractiveness, and physical attractiveness on social trade engagement. The factors that cause a person to continue using MOOCs, and the variables studied are openness, reputation, usefulness, enjoyment, confirmation, and satisfaction [10]. However, their research did not examine factors such as user or technology characteristics.

On the other hand, Zhu and Wang [11] in their research, built a research model on the intention of continuous learners who combine attachment theory and social technology system theory. Sustainability intentions are positively influenced by word of mouth, personalization services, functional attachments, emotional attachments. Unfortunately, this study did not in-depth study the direct effects between variables in the socio-technical system and MOOC continuance intentions [12].

Based on previous researches, this study's contribution is to combine technology attractiveness theory and expectation confirmation model to evaluate a user's desire to keep learning using MOOC with zenius.net as a case study. With its result, this study is expected to provide recommendations to MOOC service providers regarding what may be considered to improve users' desire to keep learning on it.

\section{Research model and hypothesis}

To evaluate the user's desire to continue to use technology is necessary to know the factors that influence it. The attractiveness of the technology itself is one of the fac- 
tors that influence users' desire to continue to use technology. Therefore, because MOOC is a technology that builds as a learning medium, it also certainly needs its attractiveness. In this study, three important aspects were used as described in previous studies, such as task attractiveness, social attractiveness, and physical attractiveness. This study used the Expectation Confirmation Model to evaluate the technology attractiveness on the user's desire to continue learning through MOOC. The illustration of the research model is shown in Figure 1 and the research hypotheses development explanation in the next section.

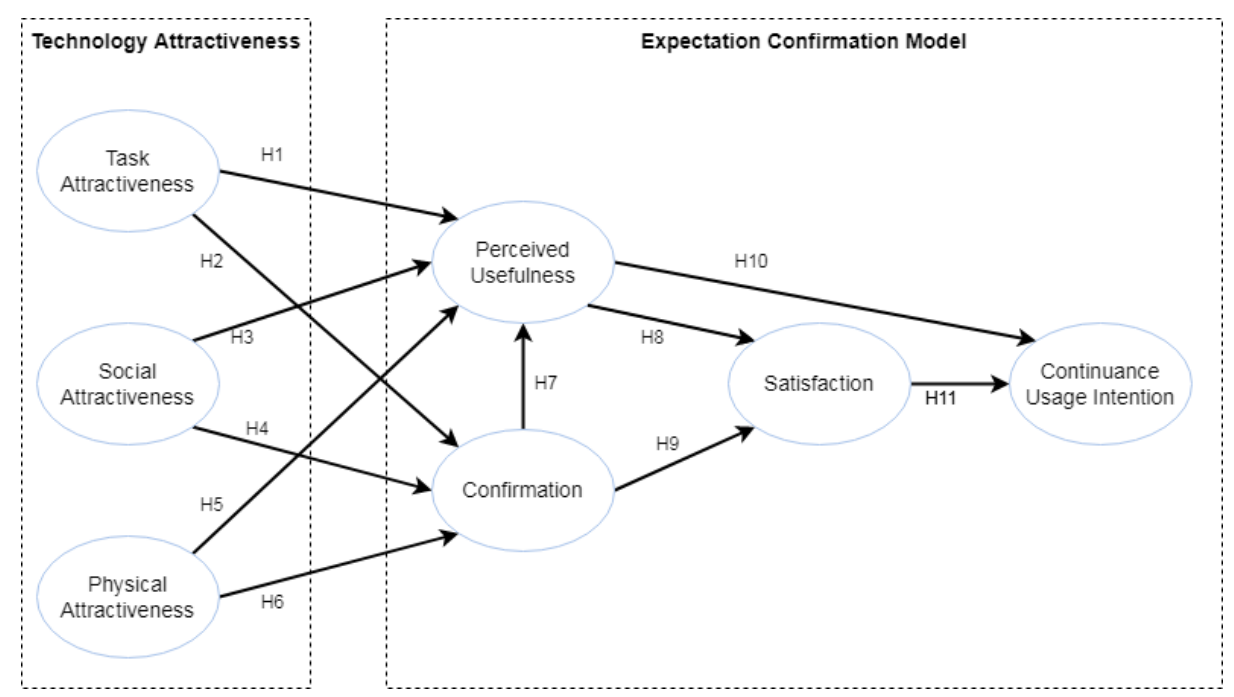

Fig. 1. Research model

\subsection{Task attractiveness, social attractiveness, and physical attractiveness}

Gavin et al. in [13] explained that task attractiveness (TA) is an interest in someone because of their ability and feasibility as partners to work together to achieve a goal. Social attractiveness (SA) is defined as attractiveness to a community because of its ability to support social interaction among its users. In this study, TA can be interpreted as the attractiveness of MOOCs in supporting social interaction between users. Social interaction in MOOC largely influences how social interaction can achieve its needs, in this case, it means helping the learning process [8].

Physical attractiveness (PA) refers to the extent to which a website is displayed well in terms of aesthetic design [8]. Visual design and aesthetics are the first and immediate impression that MOOC makes on its users and can influence the user experience during the whole process of social interaction [8]. In this case, MOOCs with higher PA will attract more attention from the users.

This explanation shows that the attractiveness of technology affects the user's perceived usefulness of MOOCs. Based on [9] research, learning content and interactivi- 
ty in MOOC are important factors that influence the intention to use it. From the discussion above, this study proposes the following hypotheses:

- Hypothesis 1 (H1). Task attractiveness affects the perceived usefulness of zenius.net.

- Hypothesis 3 (H3). Social attractiveness affects the perceived usefulness of zenius.net.

- Hypothesis 5 (H5). Physical attractiveness affects the perceived usefulness of zenius.net.

The use of technology, appearance, and information design must be considered critical factors of a website design to provide a good user [14], [15]. Confirmation (CNF) is the degree to which the actual user experience can accept the initial expectations or desires [9]. Good design and information provision are essential aspects of technology attractiveness, which means that it affects users' wishes or expectations, which affect confirmation. To determine the effect of technology attractiveness on the confirmation, the next hypothesis in this study is:

- Hypothesis 2 (H2). Task attractiveness affects confirmation of using zenius.net.

- Hypothesis 4 (H4). Social attractiveness confirmation of using zenius.net.

- Hypothesis 6 (H6). Physical attractiveness affects confirmation of using zenius. net.

\subsection{Perceived usefulness}

The expectation Confirmation Model predicts that the level of confirmation (CNF) can affect perceived usefulness (PU) [16]-[18]. Confirmation (CNF) is the degree to which the actual user experience can accept the initial expectation or desire. Perceived usefulness (PU) is understood as a utilitarian evaluation of an information system [19]. Therefore, this study offers the next hypothesis as follows:

- Hypothesis 7 (H7). Confirmation affects the perceived usefulness of zenius.net.

\subsection{Satisfaction}

Several studies state that perceived usefulness has a significant effect on satisfaction (SAT). Roca, Chiu, and Martinez in [20] say that the perceived usefulness of adult learners who participate in e-learning significantly affects the satisfaction they feel. In other research, Thong, Hong, and Tam also found that the perceived usefulness of mobile internet services has a significant effect on adult user satisfaction [18]. This is also aligned to the statement from [21], if technology can help users improve their performance, then the technology is felt to be useful [22]. From these statements, a hypothesis is proposed to find out how the perceived usefulness of MOOCs affects user satisfaction.

- Hypothesis 8 (H8). Perceived Usefulness affects the satisfaction of zenius.net. 
In addition to PU, several studies also state that confirmation (CNF) has a positive relationship to satisfaction [16], [18], [23], [24]. When the actual use experience matches or exceeds initial expectations, there is confirmation that led to user satisfaction (SAT) because the expected benefits of using information systems are realized [9]. MOOC users will compare their experience with their initial expectations when using MOOC, if their expectations were confirmed, they would be satisfied with MOOC.

- Hypothesis 9 (H9). Confirmation affects the satisfaction of zenius.net.

\subsection{Continuance usage intention}

Luarn and Lin in [25] stated that people tend to use cellular service systems because they find such systems useful for their banking transactions. Yang in [26] shows that perceived benefits drive mobile banking adoption even though the Mobile Financial System has some limitations. In addition, ECM predicts that perceived usefulness can directly determine continuance intentions [27]. Thus, the researcher assumes that perceived usefulness directly affects continuance use intentions (CUI) and formulates hypothesis as below:

- Hypothesis 10 (H10). Perceived usefulness affects continuance usage intention of zenius.net.

Satisfaction influences the use of a technology, which explains that a user's intention to continue using a particular service or system is primarily determined by their satisfaction with previous experiences. Deng et al. in [28] said that only satisfied users will choose to return to using Mobile Instant Messaging. This is also aligned with the research of Alraimi et al. who found that satisfaction had a positive effect on continuance intention from using MOOC (CUI) [9].

- Hypothesis 11 (H11). Satisfaction affects continuance usage intention of zenius. net.

\section{$3 \quad$ Methodology}

To evaluate this research model and hypotheses, a survey instrument is created based on indicators of each variable used in the research model in Fig 1. The survey questionnaire created is essentially TAM measurement, which has been adopted from previous researches [16], [29]-[32]. This questionnaire aims to find out the part of the Technology Attractiveness factor that has a significant effect on zenius.net users. All indicators are measured on a positive 5-point Likert scale where possible answers range from strongly disagreeable (1) to strongly agree (5).

The questionnaire was distributed online through social media. The social media that the researcher uses are Instagram, Facebook, Twitter, and Line. In addition, the researcher sent a direct message to the Zenius Official Account to help disseminate 
this questionnaire. After collecting the data, the researcher processed the data in the form of data cleaning, ensuring that the value (Likert Scale 5 points) that had been entered by the respondents was valid and consistent. The technique that the researcher uses to analyze the respondent's data is Structural Model Equation (SEM) using SmartPLS software.

\section{$4 \quad$ Results and discussion}

\subsection{Respondent demographics}

From the distributed survey, we got as many as 164 respondents. Based on this research, $68.3 \%$ of respondents are between 19 and 21 years old; $21.3 \%$ of respondents are aged between 16 and 18 years; $6.7 \%$ of respondents are more than 21 years old; $3.7 \%$ of respondents are between 12 and 15 years old. In terms of their latest education, $49.4 \%$ of high school graduates; $48.8 \%$ of respondents are bachelor/diploma graduates; $0.6 \%$ high school graduates; the rest are high school alumni and gap years. In terms of domicile, $24.4 \%$ came from Depok; $23.8 \%$ of respondents came from Jakarta; $4.2 \%$ came from Bogor; $10.4 \%$ came from Tangerang; $12.8 \%$ came from Bekasi; the rest came from outside Jabodetabek.

\subsection{Measurement model analysis}

Before doing the measurement model test, we clean out the outlier data. After cleaning the data, at the measurement model test stage, validity and reliability tests are carried out.

The validity test consists of convergent validity (loading factor and Average Variance Extracted (AVE)) and discriminant validity (cross-loading). From the results of the loading factor contained in Table 1, it is found that 2 parameters whose loading factor values are less than 0.7 , namely TA4 and PU4 so that we do a trial and error by removing the one with the smallest loading factor value, namely PU4 and still getting an indicator that has the loading factor value less than 0.7, then we deleted both of them which finally got all the parameters passed the factor loading test. Then we continued to test the validity with AVE and it was found that all constructs had an AVE value $>0.7$ according to Table 1 .

We also conducted a discriminant validity test using cross-loading and it was found that there was no measurement parameter whose value was lower than the other measurement parameters for the construct he built. Thus, the measurement model used has met the validity test.

Finally, we conducted a reliability test consisting of Cronbach alpha (CA) and Composite Reliability (CR). Based on Table 1, it is found that each construct has a $\mathrm{CA}$ and CR value greater than 0.7. Thus, the measurement model used has also met the reliability test. 
Table 1. Loading factors, CA, CR, and AVE

\begin{tabular}{|c|c|c|c|c|}
\hline Parameter & Loading factors $(>0.7)$ & $\mathrm{CA}(>0.7)$ & CR $(>0.7)$ & $\operatorname{AVE}(>0.5)$ \\
\hline TA1 & 0.716 & \multirow{4}{*}{0.707} & \multirow{4}{*}{0.834} & \multirow{4}{*}{0.627} \\
\hline TA2 & 0.788 & & & \\
\hline TA3 & 0.783 & & & \\
\hline TA4 & 0.682 & & & \\
\hline SA1 & 0.702 & \multirow{4}{*}{0.793} & \multirow{4}{*}{0.866} & \multirow{4}{*}{0.619} \\
\hline SA2 & 0.884 & & & \\
\hline SA3 & 0.822 & & & \\
\hline SA4 & 0.726 & & & \\
\hline PA1 & 0.831 & \multirow{4}{*}{0.868} & \multirow{4}{*}{0.910} & \multirow{4}{*}{0.718} \\
\hline PA2 & 0.795 & & & \\
\hline PA3 & 0.918 & & & \\
\hline PA4 & 0.841 & & & \\
\hline CNF1 & 0.862 & \multirow{3}{*}{0.854} & \multirow{3}{*}{0.911} & \multirow{3}{*}{0.774} \\
\hline CNF2 & 0.914 & & & \\
\hline CNF3 & 0.863 & & & \\
\hline PU1 & 0.806 & \multirow{5}{*}{0.822} & \multirow{5}{*}{0.882} & \multirow{5}{*}{0.652} \\
\hline PU2 & 0.798 & & & \\
\hline PU3 & 0.806 & & & \\
\hline PU4 & 0.594 & & & \\
\hline PU5 & 0.781 & & & \\
\hline SAT1 & 0.884 & \multirow{3}{*}{0.878} & \multirow{3}{*}{0.925} & \multirow{3}{*}{0.804} \\
\hline SAT2 & 0.898 & & & \\
\hline SAT3 & 0.908 & & & \\
\hline CUI1 & 0.938 & \multirow{3}{*}{0.928} & \multirow{3}{*}{0.952} & \multirow{3}{*}{0.869} \\
\hline CUI2 & 0.961 & & & \\
\hline CUI3 & 0.897 & & & \\
\hline
\end{tabular}

\subsection{Structural model analysis}

To test each proposed hypothesis, we conducted structural model tests. This test is done by comparing the p-value for each hypothesis to the alpha value $(0.05)$. Of the 11 hypotheses formulated, only three were rejected. Successfully proven hypotheses can be seen through $\mathrm{P}$ values that have a value less than alpha (0.05).

Hypothesis 1, hypothesis 2, and hypothesis 3 formulate that Task Attractiveness, Social Attractiveness, and Physical Attractiveness affect Perceived Usefulness. This study proved that Task Attractiveness affects Perceived Usefulness, but not so with Social Attractiveness and Physical Attractiveness.

Hypothesis 4, hypothesis 5, and hypothesis 6 formulate that Task Attractiveness, Social Attractiveness, and Physical Attractiveness influence Confirmation. This study proved that all three hypotheses were accepted. This is in line with the allegation that technology attractiveness may affect user acceptance of MOOC usage expectations. 
Hypothesis 7 formulates that Confirmation affects Perceived Usefulness. Hypothesis 8, and Hypothesis 9 formulate that Perceived Usefulness and Confirmation affect satisfaction. This study proved that both hypotheses were accepted.

Table 2. Structural test

\begin{tabular}{|l|c|c|c|c|c|}
\hline Hypothesis & $\begin{array}{c}\text { Original } \\
\text { Sample (O) }\end{array}$ & $\begin{array}{c}\text { Sample Mean } \\
(\mathbf{M})\end{array}$ & $\begin{array}{c}\text { Standard Devia- } \\
\text { tion (STDEV) }\end{array}$ & $\begin{array}{c}\text { T Statistics } \\
(\mid \mathbf{O} / \text { STDEV } \mid)\end{array}$ & $\begin{array}{c}\text { P } \\
\text { Values }\end{array}$ \\
\hline $\mathrm{H} 1$ & 0.177 & 0.180 & 0.082 & 2.169 & 0.031 \\
\hline $\mathrm{H} 2$ & 0.388 & 0.390 & 0.065 & 5.927 & 0,000 \\
\hline $\mathrm{H} 3$ & -0.095 & -0.093 & 0.054 & 1.767 & 0.078 \\
\hline $\mathrm{H} 4$ & 0.134 & 0.143 & 0.056 & 2.414 & 0.016 \\
\hline $\mathrm{H} 5$ & 0.115 & 0.119 & 0.078 & 1.472 & 0.142 \\
\hline $\mathrm{H} 6$ & 0.412 & 0.409 & 0.066 & 6.236 & 0,000 \\
\hline $\mathrm{H} 7$ & 0.541 & 0.536 & 0.076 & 7.090 & 0,000 \\
\hline $\mathrm{H} 8$ & 0.524 & 0.531 & 0.076 & 6.915 & 0,000 \\
\hline $\mathrm{H} 9$ & 0.254 & 0.25 & 0.086 & 2.948 & 0.003 \\
\hline $\mathrm{H} 10$ & 0.077 & 0.085 & 0.110 & 0.694 & 0.488 \\
\hline $\mathrm{H} 11$ & 0.224 & 0.221 & 0.106 & 2.107 & 0.036 \\
\hline
\end{tabular}

Hypothesis 10 and hypothesis 11 formulate that Satisfaction and Perceived Usefulness influence Continuance Usage Intention. This research can prove that satisfaction affects continuance usage intentions. However, this study did not succeed in proving that Perceived Usefulness may influence Continuance Usage Intention.

Structural model tests show that of all proposed hypotheses, three hypotheses have a p-value of more than the alpha value. The three hypotheses are H3 (Social Attractiveness affects perceived usefulness of zenius.net) with a p-value of 0.071, H5 (Physical Attractiveness affecting perceived usefulness of zenius.net) with a p-value of 0.141 , and $\mathrm{H} 10$ (Perceived Usefulness affecting continuance usage intention of zenius.net) with a p-value of 0.465 . The conclusions obtained are that $\mathrm{H} 3, \mathrm{H} 5$, and H10 were rejected.

\subsection{Discussion}

Research evaluating the influence of Technology Attractiveness factors on users' desire to keep learning through MOOC using the Expectation Confirmation Model (ECM) found that the study successfully built validated models as well as evaluated the influence of Technology Attractiveness factors on users' desire to keep learning through MOOC. The results of the analysis that have been discussed in the Results and Discussion chapter prove that the desire of users to keep learning through MOOC is influenced by all three factors of Technology Attractiveness, namely Task Attractiveness, Social Attractiveness, and Physical Attractiveness. 


\section{Conclusion}

This research has not been able to prove the direct influence of the three factors of Technology Attractiveness on the desire of users to keep learning through MOOC. However, other factors bridge these two things. The relationship of each of these factors will be explained as follows. The user's desire to keep learning through MOOC is directly influenced by the level of user satisfaction with MOOC. User satisfaction is directly affected by the benefits felt by the user as well as the user's evaluation of his or her expectations on the MOOC. The benefits felt by users are directly affected by Task Attractiveness and the user's evaluation of his or her expectations on MOOC. While the user's evaluation of their expectations on MOOC is directly influenced by the three factors of Technology Attractiveness, namely Task Attractiveness, Social Attractiveness, and Physical Attractiveness.

\section{Implication}

The results of this study have contributed to the realm of research (theoretical) and practice. Theoretically, this study opens up opportunities for researchers in the future to conduct more in-depth research on Task Attractiveness, Social Attractiveness, and Technology Attractiveness. That way, in practice, MOOC developers can pay attention to these three factors in more detail in developing MOOC applications.

So far, in practice, several things need to be considered by developers in developing MOOC. First, developers need to pay attention to the aesthetics/interface design of the MOOC application. This is done so that the Physical Attractiveness factor in MOOCs can be optimized. Second, developers need to pay attention to the ease of interaction between users in the MOOC application. This is done to optimize the Social Attractiveness factor in MOOC. Third, developers need to pay attention to the availability of valuable and accurate information for users to complete every activity from the course they register with MOOC. That way, the Task Attractiveness factor in MOOCs can be optimized.

\section{$7 \quad$ Limitations and suggestions for future research}

This research provides insight into technology attractiveness factors that have a significant effect on MOOC users. From this study, there is a limit. First, the demographics of respondents that researchers get are uneven. This is because respondents with their last level of education, bachelor/diploma, and high school dominate. Second, this study has not examined in-depth or specifics related to the Technology Attractiveness factor. It's general. Therefore, further research models can be developed in more detail.

Further research is expected to examine more deeply one of the factors of Technology Attractiveness, Physical Attractiveness. This factor focuses more on HumanComputer Interaction (HCI). The sample obtained in the next study was more evenly 
distributed, especially in terms of the last education. Thus, the overall data is more representative. This research has not included recommendations for efficient and effective MOOC systems for MOOC users with different types of learning styles (Visual, Auditory, Kinesthetic).

\section{$8 \quad$ References}

[1] A. Babori, "Trends in MOOCs research: Analysis of educational technology journals," Int. J. Emerg. Technol. Learn., vol. 15, no. 17, pp. 47-70, 2020. https://doi.org/10.3991/ijet.v1 $\underline{5 i 17.14637}$

[2] E. R. Blum, T. Stenfors, and P. J. Palmgren, "Benefits of massive open online course participation: deductive thematic analysis," J. Med. Internet Res., vol. 22, no. 7, p. e17318, 2020. https://doi.org/10.2196/17318

[3] J. Y. Hsu, C. C. Chen, and P. F. Ting, "Understanding MOOC continuance: An empirical examination of social support theory," Interact. Learn. Environ., vol. 26, no. 8, pp. 11001118, 2018. https://doi.org/10.1080/10494820.2018.1446990

[4] D. Shah, "By The Numbers: MOOCs in 2018," Class Central, 2018. https://www.classcent ral.com/report/mooc-stats-2018/

[5] A. Ahearn, "Stop Asking About Completion Rates: Better Questions to Ask About MOOCs in 2019," EdSurge, 2018. https://www.edsurge.com/news/2018-11-28-stop-askin g-about-completion-rates-better-questions-to-ask-about-moocs-in-2019

[6] W. You, "Research on the Relationship between Learning Engagement and Learning Completion of Online Learning Students," pp. 102-117. https://doi.org/10.3991/ijet.v17i01 .28545

[7] H. B. Seta, T. Wati, A. Muliawati, and A. N. Hidayanto, "E-Learning Success Model: An Extention of DeLone \& McLean IS'Success Model," Indones. J. Electr. Eng. Informatics, vol. 6, no. 3, pp. 281-291, 2018. https://doi.org/10.3991/ijet.v17i01.28545

[8] X. L. Shen, Y. J. Li, Y. Sun, Z. Chen, and F. Wang, "Understanding the role of technology attractiveness in promoting social commerce engagement: Moderating effect of personal interest," Inf. Manag., vol. 56, no. 2, pp. 294-305, 2019. https://doi.org/10.1016/j.im.2018. $\underline{09.006}$

[9] A. P. Oghuma, C. F. Libaque-Saenz, S. F. Wong, and Y. Chang, "An expectationconfirmation model of continuance intention to use mobile instant messaging," Telemat. Informatics, vol. 33, no. 1, pp. 34-47, 2016. https://doi.org/10.1016/j.tele.2015.05.006

[10] K. M. Alraimi, H. Zo, and A. P. Ciganek, "Understanding the MOOCs continuance: The role of openness and reputation," Comput. Educ., vol. 80, pp. 28-38, 2015. https://doi.org/ 10.1016/j.compedu.2014.08.006

[11] X. Zhu and Y. Wang, "An Empirical Study on the Users' Continuance Intention about MOOC: Based on Attachment Theory," Proc. - 2018 Int. Symp. Educ. Technol. ISET 2018, pp. 209-213, 2018. https://doi.org/10.1109/ISET.2018.00054

[12] M. M. Mohan, P. Upadhyaya, and K. R. Pillai, "Intention and barriers to use MOOCs: An investigation among the post graduate students in India," Educ. Inf. Technol., vol. 25, no. 6, pp. 5017-5031, 2020. https://doi.org/10.1007/s10639-020-10215-2

[13] J. Gavin, D. Rees-Evans, A. Duckett, and M. Brosnan, "The attractiveness, trustworthiness and desirability of autistic males' online dating profiles," Comput. Human Behav., vol. 98, no. April, pp. 189-195, 2019. https://doi.org/10.1016/j.chb.2019.04.016 
[14] Gallant, Irizarry, and Kreps, "User-Centric Hospital Web Sites: A Case for Trust and Personalization," e-Service J., vol. 5, no. 2, p. 5, 2007. https://doi.org/10.2979/esj.2007.5.2

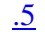

[15] Z. Jiang and I. Benbasat, "The effects of presentation formats and task complexity on online consumers' product understanding," MIS Q. Manag. Inf. Syst., vol. 31, no. 3, pp. 475-500, 2007. https://doi.org/10.2307/25148804

[16] A. Bhattacherjee, "Understanding Information Systems Continuance: An ExpectationConfirmation Model," MIS Quarterly, vol. 25, no. 3, pp. 351-370, 2001. https://doi.org/10. 2307/3250921

[17] M. C. Lee, "Explaining and predicting users' continuance intention toward e-learning: An extension of the expectation-confirmation model," Comput. Educ., vol. 54, no. 2, pp. 506516, 2010. https://doi.org/10.1016/j.compedu.2009.09.002

[18] J. Y. L. Thong, S. J. Hong, and K. Y. Tam, "The effects of post-adoption beliefs on the expectation-confirmation model for information technology continuance," Int. J. Hum. Comput. Stud., vol. 64, no. 9, pp. 799-810, 2006. https://doi.org/10.1016/j.ijhcs.2006.05.0 01

[19] H. W. You, "Students' Perception about Learning using MOOC," Int. J. Emerg. Technol. Learn., vol. 14, no. 18, p. 203, 2019. https://doi.org/10.3991/ijet.v14i18.10802

[20] J. C. Roca, C. M. Chiu, and F. J. Martínez, "Understanding e-learning continuance intention: An extension of the Technology Acceptance Model," Int. J. Hum. Comput. Stud., vol. 64, no. 8, pp. 683-696, 2006. https://doi.org/10.1016/j.ijhcs.2006.01.003

[21] L. Leung and C. Chen, "E-health/m-health adoption and lifestyle improvements: Exploring the roles of technology readiness, the expectation-confirmation model, and health-related information activities," Telecomm. Policy, vol. 43, no. 6, pp. 563-575, 2019. https://doi.or g/10.1016/j.telpol.2019.01.005

[22] A. Ramadhan, A. N. Hidayanto, G. A. Salsabila, I. Wulandari, J. A. Jaury, and N. N. Anjani, "The effect of usability on the intention to use the e-learning system in a sustainable way: A case study at Universitas Indonesia," Educ. Inf. Technol., pp. 1-34, 2021. https://doi.org/10.1007/s10639-021-10613-0

[23] A. Bhattacherjee and G. Premkumar, "Theoretical Model and Longitudinal Test Article in Belief and Changes Understanding Information Attitude Toward Tech nology A Theoretical Usage : Model and Longitudinal," Manag. Inf. Syst., vol. 28, no. 2, pp. 229254, 2012. https://doi.org/10.2307/25148634

[24] V. Venkatesh, J. Y. L. Thong, F. K. Y. Chan, P. J. H. Hu, and S. A. Brown, "Extending the two-stage information systems continuance model: Incorporating UTAUT predictors and the role of context," Inf. Syst. J., vol. 21, no. 6, pp. 527-555, 2011. https://doi.org/10.1111/ j.1365-2575.2011.00373.x

[25] P. Luarn and H. H. Lin, "Toward an understanding of the behavioral intention to use mobile banking," Comput. Human Behav., vol. 21, no. 6, pp. 873-891, 2005. https://doi.or g/10.1016/j.chb.2004.03.003

[26] A. S. Yang, "Exploring adoption in Mobile Banking Services," Can. J. Adm. Sci., vol. 26, no. April, pp. 136-149, 2009. https://doi.org/10.1002/cjas.102

[27] E. K. Budiardjo, G. Pamenan, A. N. Hidayanto, and E. Cofriyanti, "The impact of knowledge management system quality on the usage continuity and recommendation intention," Knowl. Manag. E-Learning An Int. J., vol. 9, no. 2, pp. 200-224, 2017. https://d oi.org/10.34105/j.kmel.2017.09.012

[28] Z. Deng, Y. Lu, K. K. Wei, and J. Zhang, "Understanding customer satisfaction and loyalty: An empirical study of mobile instant messages in China," Int. J. Inf. Manage., vol. 30, no. 4, pp. 289-300, 2010. https://doi.org/10.1016/j.ijinfomgt.2009.10.001 
[29] D. Cyr, M. Head, and A. Ivanov, "Design aesthetics leading to m-loyalty in mobile commerce," Inf. Manag., vol. 43, no. 8, pp. 950-963, 2006. https://doi.org/10.1016/j.im.20 $\underline{06.08 .009}$

[30] E. T. Loiacono, R. T. Watson, and D. L. Goodhue, "WebQual: An instrument for consumer evaluation of web sites," Int. J. Electron. Commer., vol. 11, no. 3, pp. 51-87, 2007. https://doi.org/10.2753/JEC1086-4415110302

[31] H. F. Lin, "Determinants of successful virtual communities: Contributions from system characteristics and social factors," Inf. Manag., vol. 45, no. 8, pp. 522-527, 2008. https://d oi.org/10.1016/j.im.2008.08.002

[32] J. Nielsen, "Iterative User-Interface Design," Computer (Long. Beach. Calif)., vol. 26, no. 11, pp. 32-41, 1993. https://doi.org/10.1109/2.241424

\section{Authors}

Syahrul A. Suriazdin is a postgraduate student of the Information Technology Master Program at the University of Indonesia, Jakarta, Indonesia.

Achmad N. Hidayanto is a lecturer and researcher (specialized in Information Technology, Information System, Business Intelligence, Technology Adoption, and Electronic Commerce, based on Google Scholar) from the Faculty of Computer Science, University of Indonesia. He also holds the position of Deputy Dean for Resources, Ventures, and General Administration. He also is one of the 10 best Indonesian researchers who is ranked 8th in 2020.

Mutia Maulida is a lecturer and researcher at the Information Technology Study Program, Faculty of Engineering, Lambung Mangkurat University. He is also an alumnus of the Master's Program in Information Technology, University of Indonesia.

Alverio Y. Kurtinus, Hanifa Arrumaisha, Nurul Aisyah, and Rico P. Pradana are the undergraduate students of the Information System at the University of Indonesia, Jakarta, Indonesia.

Article submitted 2021-12-10. Resubmitted 2022-01-23. Final acceptance 2022-01-26. Final version published as submitted by the authors. 